Mykola Talavyria

Oleksandr Talavyria

\title{
1.5. FROM BIOECONOMICS TO SUSTAINABLE DEVELOPMENT
}

\begin{abstract}
Summary
To find an effective mechanism to improve the development of rural areas of Ukraine and proposed funding measures of state support of the villages in a globalized economy that meets the requirements of time, will accelerate socio-economic growth and Ukraine in general. This process needs to describe the methodological foundations and principles of organizational and economic mechanism, the theoretical position about the nature of the mechanism of state support for rural development, their genesis and the priorities of rural development. The content of organizational and economic mechanism of state support for rural development is to be extended and systematized into methodological approaches and their application under market conditions.
\end{abstract}

Keywords: mechanism, support, development, rural areas, financing

\section{Introduction}

Sustainable development refers to a mode of human development in which resource use aims to meet human needs while ensuring the sustainability of natural systems and the environment, so that these needs can be met not only in the present, but also for generations to come. The term "sustainable development" was used by the Brundtland Commission, which coined what has become the most often-quoted definition of sustainable development: "development that meets the needs of the present without compromising the ability of future generations to meet their own needs" (United Nations, 1987; Smith and Rees, 1998).

Sustainable development ties together concern for the carrying capacity of natural systems with the social challenges faced by humanity. As early as the 1970s, „sustainability” was employed to describe an economy ,in equilibrium with basic ecological support systems" (Stivers, 1976). Ecologists have pointed to The Limits to Growth, (Meadows et al., 1972) and presented the alternative of a ,steady state economy" (Daly, 1973) in order to address environmental concerns.

The concept of sustainable development may generally be broken down into three constituent parts: environmental sustainability, economic sustainability and sociopolitical sustainability.

\section{Concept of sustainable development}

In 1987, the United Nations released the Brundtland Report, which included what is now one of the most widely recognised definitions: „Sustainable development is 
development that meets the needs of the present without compromising the ability of future generations to meet their own needs."

According to the same report, the above definition contains two key concepts:

- the concept of "needs", in particular the essential needs of the world's poor, to which overriding priority should be given;

- the idea of limitations imposed by the state of technology and social organization on the environment's ability to meet present and future needs.

The domain of economics is fundamental to considerations of sustainable development, however there has been considerable criticism of the tendency to use the three-domain model of the triple bottom line: economics, environment and social. This approach is challenged to the extent that it treats the economy as the master domain, or as a domain that exists outside of the social; it treats the environment as a world of natural metrics; and it treats the social as a miscellaneous collection of extra things that do not fit into the economic or environmental domains. In the alternative Circles of Sustainability approach, the economic domain is defined as the practices and meanings associated with the production, use, and management of resources, where the concept of 'resources' is used in the broadest sense of that word.

The domain of "ecology" has been difficult to resolve because it too has a social dimension. Some research activities start from the definition of green development to argue that the environment is a combination of nature and culture. However, this has the effect of making the domain model unwieldy if culture is to be considered a domain in its own right. Others write of ecology as being more broadly at the intersection of the social and the environmental, hence, ecology. This movement allows culture to be used as a domain alongside economics and ecology (Scerri and James, 2010).

The sustainability of human settlements is implicit in the focus of study into the relationship between humans and their natural, social and built environments. Also termed human ecology, this broadens the focus of sustainable development to include the domain of human health. Fundamental human needs such as the availability and quality of air, water, food and shelter are also the ecological foundations for sustainable development. White et al. (2013) addressing public health risk through investments in ecosystem services can be a powerful and transformative force for sustainable development which, in this sense, extends to all species (IISD Annual Report, 2011-2012).

Focusing on other aspects, some researchers and institutions have pointed out that a fourth dimension should be added to the dimensions of sustainable development, since the triple-bottom-line dimensions of economic, environmental and social do not seem to be enough to reflect the complexity of contemporary society. In this context, the Agenda 21 for culture and the United Cities and Local Governments (UCLG) Executive Bureau lead the preparation of the policy statement "Culture: Fourth Pillar of Sustainable Development", passed on 17 November 2010, in the framework of the World Summit of Local and Regional Leaders - 3rd World Congress of UCLG, held in Mexico City. This document inaugurates a new perspective and points to the relation between culture and sustainable development through a dual approach: developing a solid cultural policy and advocating a cultural dimension in all public 
policies. (Constanza et al., 1993) The Network of Excellence „Sustainable Development in a Diverse World", sponsored by the European Union, integrates multidisciplinary capacities and interprets cultural diversity as a key element of a new strategy for sustainable development. The Circles of Sustainability approach defines the cultural domain as practices, discourses, and material expressions, which, over time, express continuities and discontinuities of social meaning. However, culture falls within the social/socio-political dimension of sustainability, and therefore the proposal for adding a fourth ,cultural” dimension has not been widely accepted.

The United Nations Global Compact Cities Programme has defined sustainable political development is a way that broadens the usual definition beyond states and governance. The political is defined as the domain of practices and meanings associated with basic issues of social power as they pertain to the organization, authorization, legitimating and regulation of a social life held in common. This definition is in accord with the view that political change is important for responding to economic, ecological and cultural challenges. It also means that the politics of economic change can be addressed. This is particularly true in relation to the controversial concept of 'sustainable enterprise' that frames global needs and risks as 'opportunities' for private enterprise to provide profitable entrepreneurial solutions. This concept is now being taught at many business schools including the Centre for Sustainable Global Enterprise at Cornell University and the Erb Institute for Global Sustainable Enterprise at the University of Michigan.

Sustainable development is an eclectic concept and a wide array of political views fall under its umbrella. The concept has included notions of weak sustainability, strong sustainability and deep ecology. Different conceptions also reveal a strong tension between ecocentrism and anthropocentrism. Many definitions and images (Visualizing Sustainability) of sustainable development coexist. Broadly defined, the sustainable development mantra enjoins current generations to take a systems approach to growth and development and to manage natural, produced, and social capital for the welfare of their own and future generations.

During the last ten years, different organizations have tried to measure and monitor the proximity to what they consider sustainability by implementing what has been called sustainability metrics and indices. This has engendered considerable political debate about what is being measured. Sustainable development is said to set limits on the developing world. While current first world countries polluted significantly during their development, the same countries encourage third world countries to reduce pollution, which sometimes impedes growth. Some consider that the implementation of sustainable development would mean a reversion to pre-modern lifestyles.

Others have criticized the overuse of the term:

„(The) word sustainable has been used in too many situations today, and ecological sustainability is one of those terms that confuse a lot of people. You hear about sustainable development, sustainable growth, sustainable economies, sustainable societies, sustainable agriculture. Everything is sustainable (Temple, 1992)."

The concept of sustainable development was originally synonymous with that of sustainability and is often still used in that way. Both terms derive from the older 
forestry term 'sustained yield', which in turn is a translation of the German term 'nachhaltiger Ertrag' dating from 1713. (Grober, 2007; Finn, 2009)

According to different sources, the concept of sustainability in the sense of a balance between resource consumption and reproduction was however applied to forestry already in the 12th to 16th century (Ehnert, 2009).

'Sustainability' is a semantic modification, extension and transfer of the term 'sustained yield'. This had been the doctrine and, indeed, the 'holy grail' of foresters all over the world for more or less two centuries. The essence of 'sustained yield forestry' was described for example by William A. Duerr, a leading American expert on forestry: "To fulfil our obligations to our descendents and to stabilize our communities, each generation should sustain its resources at a high level and hand them along undiminished. The sustained yield of timber is an aspect of man's most fundamental need: to sustain life itself." - it is a fine anticipation of the Brundtlandformula (Grober, 2007).

Not just the concept of sustainable development, but also its current interpretations have its roots in forest management. Strong sustainability stipulates living solely off the interest of natural capital, whereas adherents of weak sustainability are content to keep constant the sum of natural and human capital (Quigley, 2008).

\section{History of the concept of sustainability}

The history of the concept of sustainability is however much older. Already in 400 BCE, Aristotle referred to a similar Greek concept in talking about household economics. This Greek household concept differed from modern ones in that the household had to be self-sustaining at least to a certain extent and could not just be consumption oriented (Ehnert, 2009).

The first use of the term "sustainable" in the modern sense was by the Club of Rome in March 1972 in its epoch-making report on the 'Limits to Growth", written by a group of scientists led by Dennis and Donella Meadows of the Massachusetts Institute of Technology. Describing the desirable „state of global equilibrium”, the authors used the word „sustainable”: „We are searching for a model output that represents a world system that is: 1.) sustainable without sudden and uncontrolled collapse; and 2.) capable of satisfying the basic material requirements of all of its people" (Grober, 2007; Finn, 2009).

Environmental sustainability is the process of making sure current processes of interaction with the environment are pursued with the idea of keeping the environment as pristine as naturally possible based on ideal-seeking behaviour. Thus, environmental sustainability demands that society designs activities to meet human needs while indefinitely preserving the life support systems of the planet. This, for example, entails using water sustainably, only utilizing renewable energy, and sustainable material supplies (e.g. harvesting wood from forests at a rate that maintains the biomass and biodiversity).

An „unsustainable situation” occurs when natural capital (the sum total of nature's resources) is used up faster than it can be replenished. Sustainability requires that human activity only uses nature's resources at a rate at which they can be replenished 
naturally. Inherently the concept of sustainable development is intertwined with the concept of carrying capacity. Theoretically, the long-term result of environmental degradation is the inability to sustain human life. Such degradation on a global scale could imply extinction for humanity.

Table 1: Relations of sustainability and consumption

\begin{tabular}{|l|l|l|}
\hline \multicolumn{1}{|c|}{$\begin{array}{c}\text { Consumption of renewable } \\
\text { resources }\end{array}$} & \multicolumn{1}{|c|}{ State of environment } & \multicolumn{1}{c|}{ Sustainability } \\
\hline $\begin{array}{l}\text { More than nature's ability to } \\
\text { replenish }\end{array}$ & Environmental degradation & Not sustainable \\
\hline $\begin{array}{l}\text { Equal to nature's ability to } \\
\text { replenish }\end{array}$ & Environmental equilibrium & Steady state economy \\
\hline $\begin{array}{l}\text { Less than nature's ability to } \\
\text { replenish }\end{array}$ & Environmental renewal & Environmentally sustainable \\
\hline
\end{tabular}

Source: own construction

The Venn diagram of sustainable development has many versions, but was first used by economist Edward Barbier (1987).

Figure 1: Scheme of sustainable development

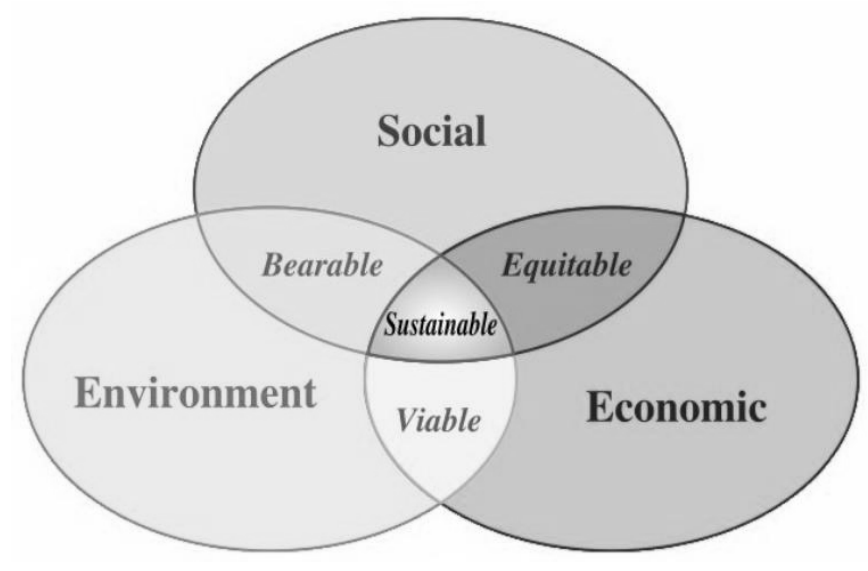

Source: based on Barbier (1987)

However, Pearce, Barbier and Markandya (1989) criticized the Venn approach due to the intractability of operationalizing separate indices of economic, environmental, and social sustainability and somehow combining them. They also noted that the Venn approach was inconsistent with the Brundtland Commission Report, which emphasized the inter-linkages between economic development, environmental degradation, and population pressure instead of three objectives. Economists have since focused on viewing the economy and the environment as a single interlinked system with a unified valuation methodology (Hamilton, 1999; Dasgupta, 2007). Intergenerational equity can be incorporated into this approach, as has become common in economic valuations of climate change economics (Heal 2009). Ruling out discrimination against future generations and allowing for the possibility of renewable alternatives to petro- 
chemicals and other non-renewable resources, efficient policies are compatible with increasing human welfare, eventually reaching a golden-rule steady state (Ayong le Kama, 2001; Endress et al., 2005). Thus the three pillars of sustainable development are interlinkages, intergenerational equity, and dynamic efficiency (Stavins et al., 2003).

Arrow et al. (2004) and other economists (e.g. Asheim,1999 and Pezzey, 1989 and 1997) have advocated a form of the weak criterion for sustainable development - the requirement than the wealth of a society, including human capital, knowledge capital and natural capital (as well as produced capital) not decline over time. Others, including Barbier 2007, continue to contend that strong sustainability - non-depletion of essential forms of natural capital - may be appropriate.

Economic development has traditionally required a growth in the gross domestic product. This model of unlimited personal and GDP growth may be over. (Korowitz, 2012) Sustainable development may involve improvements in the quality of life for many but, particularly for the affluent, may necessitate a decrease in resource consumption. (Brown, 2011) Scheme of sustainable development: at the confluence of three constituent parts.

\section{From sustainability to bioeconomics}

"Sustainable development" constitutes a new, and a yet little analyzed semantic element in the discourse of economists and environmentalists. Beyond the broad consensus which has evolved around this notion, the various currents and schools of thought are competing to establish which theory will prove best adapted to explicate the concept and render its contents usable.

The objective of "sustainability" stresses, inter alia, the need for present and future economic development to be conducted with respect for the environmental and for its evolution. This challenge means that, one way or another, economic and ecological dynamics must simultaneously be taken into account. According to Robert Costanza et. al. (1993, p. 546.), the theoretical project currently at temping to bring together economic and ecological principals have their origin in works belonging to the field of "bioeconomics". (Constanza, 1993) However, this line of research is to be explored, it should be emphasized from the outset that the expression "bioeconomics" its polysemic. It is uses with various acceptations to refer to very different theories and models of economic and ecological analysis. One might, it is true, eliminate some of these theories and retains only those already established in the theoretical corpus of economic science, of those referring explicitly to the "sustainable development" problematic. Yet, in this writers view, such a "disciplinary" attitude would be tantamount to answering the epistemological questions raised by the science of "sustainability" before those questions are really posed. On the other hand, consideration of bioeconomics in all its acceptations and ramifications, would seem a useful way of reaching an understanding of the issues and challenges of the bodies of knowledge interwoven around the notion of sustainable development, as much for its definition as for its analytical content. Indeed, although they are very different, the various bioeconomics do share, as their name suggest, the common project of sacking 
to link the teaching of the living sciences with those of economics. In doing this, these theories seek to transcend certain existing theoretical splits, and to establish a crossdisciplinary dynamic conducive to the elaboration of criteria for judgment and to the definition of prescriptions in the environmental domain. Thus, even if these bioeconomics analyses are not directly produced by the sustainability problematic (which in fact they predate), they may in the end find their place within it, by virtue of the epistemological project motivating them.

\section{Sustainability and the challenge of climate change}

Sustainability has long been part of various discussions regarding agriculture but has considerably come to the forefront in the recent years. At the Copenhagen Conference on Climate Change (December 2009), the use of genetically modified (GM) crops for biofuels was suggested as a sustainable option for developing countries, triggering intense discussion and debate. In March 2010, at the Bonn Climate Change Conference, GM crops were again part of the discussion, this time regarding sustainable land use. GM crops and sustainability remained a heated topic at the United Nations Framework Convention on Climate Change in Cancun, Mexico, in December 2010. Clearly, sustainability and its relation to the bioeconomy, biofuels, and biotechnology is increasingly important. The 15th International Consortium on Applied Bioeconomy Research (ICABR) held its annual conference near Rome, Italy (June 26-29, 2011) to examine this issue from four perspectives.

The first key aspect regarding sustainability in agriculture is the contribution of agricultural biotechnology to biodiversity, greenhouse gas (GHG) reduction, and adaption to climate change. Several recent studies have begun to quantify some of these benefits (Brookes \& Barfoot, 2006; Carpenter, 2010; Smyth et al., 2011). James (2011) identified that in 2010 the production of transgenic/GM crops reached 148 million hectares. Cumulatively, since 1996, one billion hectares of transgenic/GM crops have been produced. James noted that it took a full 10 years to reach the 500 million-hectare level, but only five years to go from 500 million hectares to one billion hectares. A total of 29 countries produced transgenic crops in 2010. With the increasingly rapid adoption of GM crops, it is important to get a firm grasp on the contribution of GM crops to environmental and economic sustainability.

The second important aspect of sustainability is the relationship between sustainability and bioenergy. Climate change impacts can be mitigated from innovative developments in bioenergy and biofuels. However, for these innovations to be globally adopted, their sustainability in the developing world has to exceed that of current technologies. Policies and regulations are - and have been - implemented to encourage technological innovations in this area, yet little research exists that can substantiate the impacts, either positive or negative.

\section{Sustainability and the society}

The third aspect is the contribution of the bioeconomy to poverty reduction and sustainable development. As James (2011) highlighted, the adoption of GM crops is 
geographically increasing and it is important to discern if the adoption of sustainable technologies are being impacted by policies and regulations in Organisation for Economic Co-operation and Development (OECD) countries. Factors of consideration here include access to new technologies, market constraints, and impacts from biosafety regulations. To ensure smallholder market participation in the benefits of GM crop adoption, it will be important to understand the institutional innovations and policy interventions that can facilitate this.

The final aspect of sustainability that merits attention is the contribution of the bioeconomy to sustainability in OECD nations. Sustainability in these nations is affected by both public and private $R \& D$ investments, innovation policy, and intellectual property rights. The trans-Atlantic divide regard GM crops and resulting products has the potential to have far-reaching global implications, and greater insights are required from both continents as to the role that the bioeconomy is having in relation to sustainability.

Bioeconomics and sustainable development is a title that covers the interactions of the natural environment with the economic process under the target of sustainable development. The concept of the Ecologically Sustainable Economic Development (ESED) emerged in the publications of the World Conservation Strategy as a policy framework to combat the environmental decay afflicting our planet, a decay mainly owed to the increasing pollution and the alarming surge in the extraction of natural resources. The ESED has grown in popularity since the publication of the Bruntlandreport (WECD, 1987). In it, the ESED is defined as 'the development that meets the need of present generations without compromising the ability of the future generations to meet their own needs" or as "a pattern of social and structural economic transformations which increase the benefits available in the present without jeopardizing the likely potentials for similar benefits in the future" (WECD, 1987). From these definitions, it is patently clear that the ESED sets a meaningful social target which, however, requires further elaboration in order to assume an operational dimension. A somewhat more precise definition, addressing policy issues, can be found also in the Brunt land report: "in essence sustainable development is a processor change in which the exploitation of resources, the direction of investments, the orientation of technological development and institutional change are all in harmony and enhance both current and future potentials to meet human needs and aspirations" (WECD, 1987). All three definitions share a common trait: the needs of present and future generations should be potentially fulfilled without trade-offs between fulfilment of present generations needs and fulfilment of future generations needs. The word "potentially" applies exclusively for the needs of future generations that cannot be brought under scrutiny at present since the preferences of future generations have-not arisen as yet, and, consequently, are unknown to us; therefore the only readily available strategy would be to waive, for the time being, the potential for fulfilment the needs of future generations, irrespective of the shape these needs may assume (Norgaard, 1994).

Two different scientific approaches dealing with the ESED were the result of two different considerations regarding the needs and preferences of future generations. These approaches are widely known as "strong" and "weak" sustainability. "Strong" 
sustainability views the needs of future generations as independent of the needs/preferences of present generations and maintains that any needs arising at and belonging to a future period may have to be formulated in a manner entirely Tracing operational conditions for the ecological sustainable economic development independent of the way present needs/preferences are currently formulated. After all, the needs and preferences of future generations may take a different shape than that assumed by the needs and preferences of present generations or even be wholly irrelevant to them. In this context, a rational policy should aim at eliminating the boundaries that stifle the formulation and fulfilment of future generations needs and preferences. As a result, the "strong" sustainability approach asserts that the ESED, offering itself as a rational policy, must, eliminate those boundaries whose cause may lie in advanced environmental degradation and inexorable exploitation of natural resources. For, once these calamities have gathered momentum, they decrease the potential welfare that generations in times to come may have. With that consideration in mind, Christensen outlines sustainable development as the development ensuring the existence of the natural environment, which acts as a basis for human welfare (Christensen, 1989).

\section{Sustainable development and renewable energy sources}

Similarly, Goodland and Ledec states that "sustainable development implies using renewable resources in a manner which does not eliminate, or degrade them, or otherwise diminish their usefulness for future generations also implies using nonrenewable mineral resources in a manner which does not unnecessarily preclude easy access to them by future generations" (Goodland and Ledec, 1987). Further, Allen argues that "sustainable utilization is a simple idea: we should utilize species and ecosystems at levels and in ways that allow them to go on renewing themselves" (Allen, 1980).

Veering towards a different direction, the approach of "weak" sustainability accepts that the needs and preferences of future generations will be similar and inane case contingent on the needs and preferences of present generations. Furthermore, the needs/preferences of future generations can be foreseen by extrapolating the evolution of current and past needs/preferences.

The essential characteristic of this approach is the assumption that future generations can substitute the fulfilment of needs and preferences pertinent to the natural environment with the fulfilment of needs and preferences pertinent to manmade elements along as one takes into account that such a substitution also holds true for both past and present generations. The assumption goes on to maintain that, because of the natural environment's degradation, the foregone utility can be substituted by the utility attained by using manmade assets and since this substitution did occur in the past it can continue in the future as well. In this context, the criterion of sustainable development is the per capita utility. As long as the per capita utility is not declining, welfare to be enjoyed by future generations, is ensured and therefore sustainability prevails. 
This rationale is based on an extension of the existing mainstream welfare criteria to future generations. Indeed, past and present generations accept a lesser fulfilment of preferences regarding the natural environment on condition that other preferences regarding manmade elements are fulfilled to a higher level. It is thus implied that environmental degradation can be continuing if accompanied by other activities which increase welfare to an extent greater than the extent to which welfare, caused by the degraded environment, is lost. Such an evolution, argues the "weak" sustainability approach, can constitute a sustainable development path. As a result, future generations can do with less environment as long as manmade assets can guarantee a non-declining per capita utility. The implicit assumption underling this argument is that future generations have similar patterns of values with present generations and hence adopt a similar trade-off ratio between environmental utility and manmade utility. In this context, Pezzey firmly states that "our standard definition of sustainable development will be the criterion of a non-declining per capita utility, because of its self-evident appeal as a criterion of intergenerational equity' (Pezzey, 1989).

Pearce et al. defines that sustainable development is a situation in which "the development vector increases monotonically over time" (Pearce et al. 1989; Pearce and Atkinson, 1993; Barbier and Markandaya, 1990).It is, therefore, evident that there exist two fundamentally different directions in the scientific interpretation of the ESED. The direction of strong sustainability supports the maintenance of the existing natural "capital" as a condition for the formulation and fulfilment of future generations needs and preferences while the direction of weak sustainability endorses the mainstream criterion of the no declining utility which implicitly permits substitution of the natural environment with manmade capital and/or assets and hence opens the way to further environmental deterioration.

Between the two directions, interpreting the ESED one may detect several approaches valuable indeed which, however, are already deficient in operationability. Indicatively, Bergh and Nijkamp (1990) define the ESED as those dynamics of economic activities, social perceptions and population which provide acceptable levels of life for every human being by ensuring availability of natural resources and ecosystems. Daly speaks of uneconomic growth and proposes physical limits in economic process and in economic growth so that the latter may be a lasting one. This "steady state", approach proposes explicitly that economic process and production should not overcome the carrying capacity of ecosystems (Daly, 1999).

Georgescu-Roegen envisages grave and irreversible scarcities of natural resources and an exacerbated pollution problem if economic production continues at its current pace. In this context, he foresees irrevocable on sustainability by which future generations will be dealt a far heavier blow (Georgescu-Roegen, 1971, 1976). It is clear from the above, that there exists a lively scientific dialogue over the ESED and an inexhaustible effort to make the concept operational and decision making relevant. Sadly, considerable lack of operation ability still remains.

As a result, future generations can do with less environment as long as manmade assets can guarantee a non-declining per capita utility. The implicit assumption underling this argument is that future generations have similar patterns of values with present generations and hence adopt a similar trade-off ratio between environmental 
utility and man-made utility. In this context, Pezzey firmly states that "our standard definition of sustainable development will be the criterion of a non-declining per capita utility, because of its self-evident appeal as a criterion of intergenerational equity" (Pezzey, 1989).

Bioeconomics and sustainable development is a title that covers the interactions of the natural environment with the economic process under the target of sustainable development. Sustainable development is development that meets the needs of the present without compromising the ability of future generations to meet their own needs.

\section{Conclusion}

The first key aspect regarding sustainability in agriculture is the contribution of agricultural biotechnology to biodiversity, greenhouse gas (GHG) reduction, and adaption to climate change.

The second important aspect of sustainability is the relationship between sustainability and bioenergy. Climate change impacts can be mitigated from innovative developments in bioenergy and biofuels. However, for these innovations to be globally adopted, their sustainability in the developing world has to exceed that of current technologies. Policies and regulations are - and have been - implemented to encourage technological innovations in this area, yet little research exists that can substantiate the impacts, either positive or negative.

The third aspect is the contribution of the bioeconomy to poverty reduction and sustainable development.

\section{References}

1. Allen, R. (1980): How To Save The World. Totowa, New Jersey: Barnes \& Noble Books

2. Arrow, K. J.; Dasgupta, P.; Goulder, L.; Daily, G.; Ehrlich, P. R.; Heal, G. M.; Levin, S.; Maler, K-G.; Schneider, S.; Starrett, D. A.; Walker, B. (2004): „Are we consuming too much?". Journal of Economic Perspectives 18 (3), pp. 147-172.

3. Asheim, G. (1999): „Economic analysis of sustainability”. In Lafferty, W. M.; Langhalle, O. Towards Sustainable Development. New York: St. Martins Press. p. 159.

4. Ayong Le Kama, A. D. (2001): „Sustainable growth renewable resources, and pollution”. Journal of Economic Dynamics and Control 25 (12), pp. 1911-1918.

5. Barbier, E. (1987): „The Concept of Sustainable Economic Development”. Environmental Conservation 14 (2), pp. 101-110.

6. Barbier, E. (2007): Natural Resources and Economic Development, Cambridge University Press.

7. Bergh, J.C.J.M. and Nijkamp, P., (1990): Ecologically sustainable economic development: concepts and model implications. Serie Research Memoranda 0002, VU University Amsterdam, Faculty of Economics, Business Administration and Econometrics.

8. Bergh, J.C.J.M. and Nijkamp, P., (1990): Ecologically sustainable economic development in a regional system: a case study in agricultural development planning in the Netherlands. Serie Research Memoranda 0003, VU University Amsterdam, Faculty of Economics, Business Administration and Econometrics. 
Talavyria, M. - Talavyria, O.

9. Brown, L. R. (2011): World on the Edge. Earth Policy Institute. Norton.

10. Carpenter, J. (2010): Peer-reviewed surveys indicate positive impact of commercialized GM crops. Nature Biotechnology, 28, pp. 319-321.

11. Christensen, C.; Shapouri, S. (1989): „Adjusting to Global Transformation: Sub-Saharan Africa and the Global Food System" in Dennis Pirages (ed.), Transforming the Global Economy, New York, Macmillian

12. Costanza, R., Wainger, L., Folke, C., and Mäler, K.-G. (1993): Modelling complex ecological economic systems, BioScience 8, pp. 545-555.

13. Daly, H. E. (1973): Towards a Steady State Economy. San Francisco, Freeman.

14. Dasgupta, P. (2007): „The idea of sustainable development”. Sustainability Science 2 (1), pp. 5-11.

15. Ehnert, I. (2009): Sustainable Human Resource Management: A Conceptual and Exploratory Analysis from a Paradox Perspective; Springer, pp. 35-36.

16. Endress, L.; Roumasset, J.; Zhou, T. (2005): „Sustainable Growth with Environmental Spillovers". Journal of Economic Behavior and Organization 58 (4): 527-547.

17. Finn, D. (2009): Our Uncertain Future: Can Good Planning Create Sustainable Communities?; University of Illinois, p. 3.

18. Georgescu-Roegen N. (1971): The Entropy Law and the Economic Process. Harvard University Press Cambridge, MA, USA.

19. Georgescu-Roegen N. (1976): The entropy law and the economic problem. In: GeorgescuRoegen, N., Ed. Energy and Economic Myths. Pergamon Press Inc, New York, NY, USA, pp. 53-60.

20. Goodland, Robert G. and George Ledec (1987): „Neoclassical economics and principles of sustainable development", Ecological Modelling, Vol. 38, pp. 19-46.

21. Grober, U. (2007): Deep roots - A conceptual history of „sustainable development”, (Nachhaltigkeit), Wissenschaftszentrum Berlin für Sozialforschung, pp. 8-9.

22. Hamilton, K.; Clemens, M. (1999): „Genuine savings rates in developing countries”. World Bank Econ Review 13 (2), pp. 333-356.

23. Heal, G. (2009): „Climate Economics: A Meta-Review and Some Suggestions for Future Research". Review of Environmental Economics and Policy 3 (1), pp. 4-21.

24. http://citiesprogramme.com/aboutus/our-approach/circles-of-sustainability;

25. IISD Annual Report (2011-2012): Bringing human health and wellbeing back into sustainable development. In: IISD Annual Report 2011-12.

26. James, C. (2011): Global status of commercialized biotech/GM crops: 2010 (ISAAA Issue Brief No. 42), Ithaca, NY: International Service for the Acquisition of Agri-biotech Applications (ISAAA).

27. Korowitz, D. (2012): Ignorance by Consensus, Foundation for the Economics of Sustainability.

28. Meadows, D.H., D.L. Meadows, J. Randers, and W.W. Behrens III. (1972): The Limits to Growth. Universe Books, New York, NY.

29. Norgaard, R. B. (1994): Development Betrayed: The End of Progress and a Coevolutionary Revisioning of the Future. London and New York. Routledge.

30. Pearce, D. (1989): Blueprint for a green economy. Earthscan Publications, London, UK, $192 \mathrm{p}$.

31. Pearce, D., A. Markandya, E. Barbier. (1990): Environmental Sustainability and CostBenefitAnalysis. Environment and Planning 22, pp. 1259-1266.

32. Pearce, D.; Atkinson, W.; Giles D., (1993): „Capital theory and the measurement of sustainable development: an indicator of „weak” sustainability," Ecological Economics, Elsevier, vol. 8(2), pp. 103-108. 
33. Pearce, D.; Markandya, A.; Barbier, E. (1989): Blueprint for a green economy. London: Earthscan.

34. Pezzey, J. (1989): „Economic Analysis of Sustainable Growth and Sustainable Development". Environmental department Working Paper No. 15 (World Bank).

35. Pezzey, J. (1997). „Sustainability constraints versus 'optimality' versus intertemporal concern, and axioms versus data". Land Economics (University of Wisconsin Press) 73 (4), pp. 448-466.

36. Quigley, M. (2008): Encyclopedia of Information Ethics and Security, Monash University, p. 623.

37. Scerri, A.; James, P. (2010): 'Accounting for Sustainability: Combining Qualitative and Quantitative Research in Developing 'Indicators' of Sustainability', International Journal of Social Research Methodology, Vol. 13, No. 1., pp. 41-53.

38. Smith, Ch.; Rees, G. (1998): Economic Development, 2nd edition. Basingstoke: Macmillan.

39. Smyth, S.J., Gusta, M., Belcher, K., Phillips, P.W.B., \& Castle, D. (2011): Environmental impacts from herbicide tolerant canola production in Western Canada. Agricultural Systems, 104, pp. 403-410.

40. Stavins, R.; Wagner, A.; Wagner, G. (2003): „Interpreting Sustainability in Economic Terms: Dynamic Efficiency Plus Intergenerational Equity”. Economic Letters 79 (3), pp. 339-343.

41. Stivers, R. (1976): The Sustainable Society: Ethics and Economic Growth. Philadelphia, Westminster Press

42. United Nations (1987): „Report of the World Commission on Environment and Development.” General Assembly Resolution 42/187, 11 December 1987. Retrieved: 200704-12.

43. White, F; Stallones, L; Last, JM. (2013): Global Public Health: Ecological Foundations. Oxford University Press.

44. World Commission on Environment and Development. „Our Common Future, Chapter 2: Towards Sustainable Development”. http://un-documents.net/ocf-02.htm. Retrieved 201109-28. 